\section{International Scientific Journal Theoretical \& Applied Science}

p-ISSN: 2308-4944 (print) e-ISSN: 2409-0085 (online)

Year: $2015 \quad$ Issue: $01 \quad$ Volume: 21

Published: $30.01 .2015 \quad \underline{\text { http://www.T-Science.org }}$
Sergey Alexandrovich Mishchik Associate Professor, Candidate of Pedagogical Science, Corresponding member of International Academy TAS, Assistant professor Department of Physics,

State Maritime University Admiral Ushakov, Russia sergeimishik@mail.ru

SECTION 21. Pedagogy. Psychology. Innovation in Education.

\title{
ERTSGAMMY - THE BASIC PRINCIPLES OF CONSTRUCTION OF THE SPACE INTEGRITY-SYSTEM ABILITY TO LIVE
}

Abstract: A three directions of ertsgammy - the basic principle of the formation of a holistic system - wide profile specialist who represents the three synergistic characteristics of the entire space of life in the simulation of its structure in the form of three stars Ertsgamma at pedagogometric modeling: system of a subject, a holistic system - cycle as a measure of communication and integrity-System foundations of accelerated learning.

Key words: pedagogometriks, consistency, integrity, livelihoods, well -profile analysis, the star Ertsgamm, academic subject, synergy, communication.

Language: Russian

Citation: Mishchik SA (2015) ERTSGAMMY - THE BASIC PRINCIPLES OF CONSTRUCTION OF THE SPACE INTEGRITY-SYSTEM ABILITY TO LIVE. ISJ Theoretical \& Applied Science 01 (21): 164-172. doi: http://dx.doi.org/10.15863/TAS.2015.01.21.28

\section{УДК 372.851}

\section{ЭРЦГАММНОСТЬ - БАЗИСНЫЙ ПРИНЦИП ПОСТРОЕНИЯ ПРОСТРАНСТВА ЦЕЛОСТНО- СИСТЕМНОЙ ЖИЗНЕДЕЯТЕЛЬНОСТИ}

Аннотация: Предложены три направления эриггаммности - базисного принцииа формирования целостно-системного иирокопрофильного специалиста, который отражает три синергетические характеристики всего пространства жизнедеятельности при моделировании его структуры в виде трёх звёзд Эригамма при педагогометрическом моделировании: системного учебного предмета, иелостносистемного ичкла как меры коммуникации и иелостно-системных основ ускоренного обучения.

Ключевые слова: педагогометрика, системность, иелостность, жизнедеятельность, широкопрофильность, анализ, звезда Эризгаммы, учебный предмет, синергетика, коммуникация.

\begin{abstract}
Эрцгаммность - есть базисный принцип формирования целостно-системного широкопрофильного специалиста, который отражает три синергетические характеристики всего пространства жизнедеятельности при моделировании его структуры в виде трёх звёзд Эрцгамма при педагогометрическом моделировании [7].

Первое направление эрцгаммности связывается с началом процесса обучения субъекта жизнедеятельности и формированием системного моделирования учебного предмета. Психолого-педагогические основы построения учебных предметов устанавливаются формированием обобщённых видов учебной деятельности. Полнота видов деятельности определяется целостно-системным циклом
\end{abstract}

жизнедеятельности. Он выделяет предметные и деятельностные виды отношений. Это определяет инвариантную форму производства социальных связей. Формирование целостно-системных представлений создаёт системные принципы мышления - особенной меры построения учебного предмета.

Естественным носителем целостносистемного учебного предмета служит обобщённое коммуникативное пространство, которое определяет особенности жизнедеятельности. Базой структуры социального отношения является целостносистемный цикл, который имеет всеобщую форму восприятия объектно-субъективных представлений. Формирование универсального типа структуры предметов коммуникативного 
пространства определяет условие целостного восприятия. Это задаёт обратный процесс воспроизводства духовного образа через эвристические формы учебных предметов [2].

Каждый учебный предмет есть отражение собственного предметного целостно-системного цикла жизнедеятельности, который задаёт соответствующее конституционное пространство проектирования учебной активности. Поэтому структура целостно-системного цикла должна отражать программу воспитания и обучения субъекта развития на протяжении всего периода коммуникативного взаимодействия $\mathrm{c}$ учебной средой. Надо установить исходное состояние субъекта, определить учебные средства, предмет и цель (продукт) учебного взаимодействия, представить опредмеченную потребность, спроектировать промежуточное и абсолютное состояние субъекта обучения. Это задаёт решение проблемы организации соответствующих видов деятельностей: всеобщей, технологической, контрольной, ритуальной, восходящей и развития.

Особенностью структуры целостносистемного цикла жизнедеятельности является его системность. Каждый элемент цикла имеет системное содержание. Первоначально представляется каждый элемент как система; определяется порождающая среда; устанавливаются целостные свойства объекта; выделяются уровни анализа; определяются межуровневые отношения; представляется структура уровня; устанавливаются структурные элементы; выделяются системообразующие связи; представляется форма организации объекта; определяются системные свойства; устанавливается поведение объекта; выделяется его развитие.

Целостно-системный подход к учебному предмету как циклическому новообразованию устанавливает интегральную цель формирования учебного предмета как программу развития субъекта учебной деятельности, формирование различных форм её обобщения и развития, а также воспитания самого субъекта. Тогда цель развития структуры цикла учебного предмета должна отражать последовательность целостносистемного наполнения программы, содержания и методов достижения установленной цели [1].

Общая структура цикла учебного предмета должна отражать программу формирования и развития субъекта учебной деятельности через её различные виды и формы в результате взаимодействия с предметными условиями в виде учебных средств и соответствующих объектов. Полнота структуры цикла учебного предмета устанавливает соответствующую форму субъекта познания.
Структурные элементы цикла учебного предмета образуют полную группу процесса познания. Устанавливаются начальные познавательные условия для субъекта учебной деятельности; выделяются учебные средства познавательной активности в форме основных методов организации данного процесса; определяется собственная программа учебного содержания предмета, соответствующая заданным учебным средствам; устанавливаются цели учебного процесса в виде соответствующих учебно-воспитательных результатов; выделяются нормативные требования к результатам обучения в форме закреплённого стандарта; определяются глобальные знания и умения субъекта, составляю-щие остаточный образ развивающейся личности на этапе собственной частичной целостности; устанавливаются абсолютные качества личности при первичном цикле их формирования.

Системообразующими связями цикла учебного предмета выступают различные виды деятельности: всеобщей, технологической, контрольной, ритуальной, восходящей и развивающей. Все виды деятельности имеют одинаковую структуру, но собственные цели, которые определяют направленную деятельность на достижение части этапа познавательного цикла учебного предмета.

Общая технология проектирования учебного предмета в форме целостно-системного цикла определяется как последовательное единство развития личности на основе последовательного освоения структурного содержания образовательного процесса. Единство принципов усвоения и трансформации целостно-системного цикла учебного процесса определяет эффективность образовательной деятельности.

Второе направление развитие принципа эрцгаммности задаётся формированием целостно-системного цикл как меры коммуникации.

Целостно-системный цикл устанавливает конституционный характер жизнедеятельности субъекта. Это определяет его отношение к миру, как образу нормативной действительности. Единство системных структур объективных условий и различных форм деятельности составляет главное условие целостной системообразующей связи между элементами цикла развития. Следовательно, совершенствование жизненного цикла должно быть направлено на формирование связей между реальными и производными элементами цикла, формами его существования.

Тогда к циклу жизнедеятельности можно применить основы её системного анализа. Выделяем элементы цикла как систему, устанавливаем порождающую среду, определяем 
целостные свойства цикла, выделяем уровни его строения, устанавливаем структуру каждого уровня, определяем структурные элементы, выделяем системообразующие связи, устанавливаем форму организации цикла, определяем системные свойства цикла по характеристикам сложности, разнообразия и упорядоченности; выделяем характер поведения цикла и устанавливаем перспективы развития цикла жизнедеятельности [3].

Процесс формирования циклов жизнедеятельности имеет трёхуровневую структуру. Окружающий мир есть гиперпространство множества циклов жизнедеятельности. В зависимости от культурного и образовательного уровня субъект жизни выбирает определённую схему целеполагания на эмпирическом или заданном теоретическом уровне. Многократное повторение ситуаций формирует жизненный опыт - момент жизнедеятельности. То есть, выделяем уровни: гиперпространство жизнедеятельности, жизненный цикл и момент жизнедеятельности.

Таким образом, целостно-системный цикл жизнедеятельности есть инвариантная модель социальных отношений, которые формируются до жизненного опыта различного эмпирического и теоретического обобщения. Уровни и фазы формирования должны пройти через все виды связи субъекта с окружающим миром. При этом целостно-системный цикл принимает меру единицы жизнедеятельности развивающегося субъекта.

Жизнедеятельность субъекта происходит в социальной среде, когда только в процессе взаимодействия с ней в виде различных форм связи формируется собственное социальное развитие субъекта. В качестве главного психологического основания процесса общения, различных форм коммуникации, можно определить своеобразный ориентировочный рефлекс общения, что и составляет предмет теоретических основ общения и коммуникативной деятельности. Естественное развития процесса коммуникации порождает различные виды еe ориентировочного компонента. Можно предположить, что максимально эффективным видом коммуникативной деятельности будет ориентация на системные отношения [4].

Системный тип ориентировки в процессе коммуникации требует детального представления всех компонентов этой фазы общения. На первом этапе она должна отвечать главному признаку процесса деятельности - его завершённости, который формирует дискретный характер коммуникативной деятельности высокого уровня разрешения. Это создаёт условия перехода ко второй фазе коммуникативной деятельности - к её собственному воспроизведению. Абсолютное, артистическое, исполнительское искусство процесса коммуникации определяется полным системным изоморфизмом ориентировочного и исполнительного компонентов процесса общения.

Опасность перехода к неуправляемым формам общения и коммуникации должно контролироваться целями конкретных действий. Необходимость полной завершённости каждого, не только контрольного действия, но и коммуникативного процесса в целом, порождает необходимость поиска эффективных приёмов выхода из данного пространства общения. Традиционные и теоретические поиски гармоничного перехода к новой фазе коммуникации требуют соблюдения трёх моментов: выделение условий достижения целей данной фазы коммуникации; соответствие типов структур ориентировочной, исполнительной и контрольной фазы; завершённость контрольной фазы коммуникации.

Выделенная трёхслойная структура коммуникативной деятельности, имеющей циклический характер, принимает инвариантную форму целостно-системного общения. Она порождает универсальную меру коммуникативной деятельности.

Совершенствование как меры коммуникативной деятельности, так и всего цикла общения требует целостно-системного восприятия мира. Он составляет предметные условия коммуникативного цикла. Системная, внешняя порождающая среда задаёт генетические условия формирования не только системного образа мира, но и компонентов деятельности общения и всего цикла жизнедеятельности. Главным направлением развития процесса общения является его совершенствование в области целостности. При этом и возникает целостно-системный цикл жизнедеятельности, который является носителем универсальной меры коммуникативной деятельности.

Выделение и формирование дискретной структуры целостно-системного цикла жизнедеятельности, как меры коммуникативной деятельности, устанавливает функциональное определение каждого структурного элемента. Определение предметной цели коммуникации закрывает её глобальный смысл - дальнейшее развитие и совершенствование субъекта жизнедеятельности. Именно развитие субъекта и его совершенствование порождает новые структурные элементы цикла, включая и «частичного» субъекта жизнедеятельности. При этом происходит смещение предметного характера деятельности на её субъектнопредметный смысл. Этим задаётся внутренняя 
динамика целостно-системного цикла коммуникативной деятельности.

Динамическое состояние цикла снимается выделением стабильных социальных целей развития субъекта. «Нужда», как мера опредмеченной потребности, задаёт новый импульс инерционного состояния общения стабильное русло жизни. Всякие внешние социальные изменения приводят к саморегуляции целостно-системного цикла коммуникативной деятельности. В этом случае формируются не только новые предметные условия коммуникации, но и перестраиваются системообразующие связи. Их структура должна обеспечивать эффективный уровень общения в условиях абсолютного фос-мажёра. Адекватный уровень коммуникативной деятельности устанавливает её степень устойчивости в эпоху социальных потрясений. Субъекты, являющиеся носителями данного уровня целостно-системного коммуникационного цикла принимают наивысший статус национального героя [5].

Целостно-системный

цикл жизнедеятельности, выполняя коммуникативные функции, в процессе собственного формирования проходит ряд этапов. Они отражают определённые аспекты психических процессов, связанные со способами ориентации человека в природе и обществе. Это требует включения всех методов и способностей субъекта. При этом вся исследовательская деятельность человека направлена на достижение абсолютной цели коммуникации. Выделение целеполагающей функции коммуникации требует дополнительных теоретических и особенно эмпирических способностей субъекта жизнедеятельности.

Любая форма целостно-системного коммуникативного цикла имеет постоянный мотивационный оттенок. Последующие фазы формирования деятельности общения эмпирически могут принимать различные формы. Однако воспитание теоретической формы коммуникативной деятельности требует последовательного включения: генеральной мотивации, ориентационной коммуникации, визуального общения, акустического образа действия, колориметрического восприятия окружающей действительности, обонятельного представления, термодинамической чувствительности, тактильной способности, рецепторной осмыслённости, знаковой деятельности, речевого взаимодействия, грамматического образа. Это порождает внутренний мир субъекта жизнедеятельности.

Радость красоты общения, когда человек чувствует уверенность во всех собственных социальных ролях, ориентируясь на инвариантный образ целостно-системного цикла коммуникации, формирует нормативную форму творческой коммуникации. Это определяет исполнительские фазы общения, которые развиваются благодаря совершенствованию ориентировочной схемы коммуникативной деятельности [6].

Врождённый рефлекс тотальной ориентировки переходит в свою противоположность - контрольный компонент коммуникации полного цикла жизнедеятельности. Все формы и фазы целостносистемного цикла коммуникации есть его сверхтонкая структура, которая устанавливает его собственно слоистый характер и их взаимодействие. При этом ориентировочноконтрольные фазы коммуникативного цикла определяются степенью отношения с внешней средой общения.

Сформированная инвариантная структура целостно-системного цикла коммуникации образует цепную реакцию множества циклов общения. Коммуникативная деятельность формируется из тринадцати основных целостносистемных циклов, которые порождают своеобразный «континиум» процесса общения. Естественно, что в процессе развития коммуникативной деятельности происходит взаимосвязь и проникновение циклов друг в друга. Степень их «интерференции» задаётся сложностью процесса общения и особенностью решения коммуникативных задач.

Множество целостно-системных циклов общения создают гиперпростанство коммуникативной жизнедеятельности. В нём можно выделить три основные направления связанные с ориентировочными, исполнительными и контрольными функциями общения. Каждый «квант» целостно-системного цикла будет иметь своеобразные три координаты ориентировочно-исполнительно-контрольного характера. В качестве начала отсчёта гиперпространства общения можно принять исходное состояние субъекта жизнедеятельности. Единицей измерения каждой оси должен являться один целостно-системный цикл между его соответствующими фазами коммуникации.

Построение гиперпространства коммуникативной жизнедеятельности доказывает дискретный характер процесса общения. Мерой общения является целостно-системный цикл жизнедеятельности, который порождает новый тип личности, ориентирующейся во всех проблемах коммуникативной деятельности. Формирование нового типа личности является главной задачей всего комплекса психологопедагогических наук в эпоху демократического развития общества.

Можно привести пример построения собственной структуры коммуникационного 
цикла на решение социальной задачи приветствия: «Здравствуйте».

1. Выделяю начальное состояние себя и собеседника коммуникативной деятельности надо ли поздороваться вообще?

2. Устанавливаю структуру всеобщей коммуникативной деятельности - вспоминаю этикет.

3. Определяю существующие средства коммуникативной деятельности - выбираю способ как поздороваться: взглядом, жестом, словом, поцелуй (4 компонента), письменная форма.

4. Выделяю строение коммуникативной деятельности - представляю как это я всё сделаю.

5. Устанавливаю представление о предмете коммуникативной деятельности - взглядом окидываю собеседника.

6. Определяю структуру контрольной коммуникативной деятельности - контролирую процесс произношения приветствия и наблюдаю за реакций собеседника.

7. Выделяю существование целостного образа коммуникативной деятельности наблюдаю состояние собеседника от произнесённого мною приветствия.

8. Устанавливаю строение ритуальной коммуникативной деятельности - ожидаю ответного приветствия, соответствующего данной ситуации.

9. Определяю материальную форму потребности коммуникативной деятельности ощущаю чувство удовлетворения или неудовлетворения от этого приветствия.

10. Выделяю структуру процесса саморазвития себя и собеседника в процессе коммуникативной деятельности - анализирую процесс собственного приветствия и соответствие ответной реакции собеседника на общение со мной.

11. Устанавливаю его промежуточное состояние себя и собеседника в процессе коммуникативной деятельности - устанавливаю промежуточное состояние себя и собеседника в процессе взаимного приветствия.

12. Определяю строение совершенствования коммуникативной деятельности - определяю для себя совершенствования следующего взаимного приветствия.

13. Установление нового содержания себя и собеседника в процессе коммуникативной деятельности - установление нового содержания себя и собеседника в процессе следующего взаимного приветствия, что определяет последующий момент нового компонента коммуникативной жизнедеятельности [8].

Третье направление развитие принципа эрцгаммности задаётся формированием целостно-системных основ ускоренного обучения. Целостно-системные основы ускоренного обучения определяются формированием обобщённых видов учебной деятельности. Полнота видов деятельности задаётся целостно-системным циклом жизнедеятельности. Он задаёт предметные и системообразующие-деятельностные виды связей. Это определяет инвариантную форму производства социального пространства. Воспитание целостно-системных представлений создаёт оперативные схемы мышления особенной меры ускоренного обучения.

Материальным носителем целостносистемного ускоренного обучения является обобщённое коммуникативное пространство, которое задаёт качество жизнедеятельности. Основой структуры социального восприятия является целостно-системный цикл, который имеет универсальную форму восприятия предметных отношений. Формирование единого типа структуры субъектов коммуникативного пространства определяет условие мгновенного восприятия мира. Это порождает экстериоризационный процесс воспроизводства внутреннего мира через творческие формы скоростной учебной деятельности [9].

Целостно-системный цикл, как форма скоростной учебной деятельности высокого уровня обобщения, задаётся: начальными требованиями к субъекту учебной деятельности, структурой всеобщей деятельности, выбором средств деятельности, определением технологической деятельности, исследованием предмета, установлением контрольной деятельности, анализом опредмеченной потребности, восходящей деятельностью, характеристиками компаунд-субъекта, развивающей деятельностью и сформированными совершенными показателями субъекта. Это определяет полноту цикла жизнедеятельности.

Особенностью структуры целостносистемного цикла скоростной учебной жизнедеятельности является его инвариантная системность. Это реализуется в обобщённой схеме системного анализа каждого структурного элемента, когда: структурный элемент рассматривается как система, определяется порождающая среда, представляются целостные свойства, выделяются уровни анализа, устанавливаются межуровневые отношения, формируется структура уровня, задаются структурные элементы, исследуются системообразующие связи, анализируется форма организации, изучаются системные свойства, исследуется поведение системы, проектируется её развитие.

Общий принцип формирования структуры цикла обучения направлен на воспроизводство 
механизма его существования в выделении ориентирующих внешних элементов процесса познания. К ним относятся три этапа развития субъекта и три фазы преобразования предметной потребности. Развитие каждого элемента происходит в процессе соответствующих видов деятельностей, которые имеют инвариантную структуру но различные цели собственного воспроизводства. Это устанавливает обобщённый принцип цикла обучения.

Цикл обучения имеет предметный и полидеятельностный характер внутренней структуры. Предметность определяется поэтапным преобразованием субъекта учебного процесса через овладения им средствами познавательной деятельности, соответствующими собственно предмету изучения и превращающегося в заданную цельпродукт исследования, структурно-изоморфного опредмеченной потребности, задающей биполярное развитие субъекта до относительно абсолютного идеала. Процесс приобретает реальное движение в результате организации последовательных форм познавательных деятельностей.

Процесс развития цикла обучения имеет динамическую структуру собственного развития. Это определяется постепенным и непрерывным совершенствованием учебной деятельности. Овладение предметом изучения приводит к смещению его фазового состояния в область нового познавательного средства, задающего следующий этап развития исследовательской активности. Принцип динамического состояния учебного цикла позволяет указать на ускоренные возможности организации познавательной деятельности, которая задаётся как относительными, так и переносными характеристиками процесса исследования социокультурной среды.

Целостность структуры цикла обучения задаётся его полнотой. Принцип исходного абсолютного состояния циклического познавательного процесса определяет его дальнейшее совершенствование, но с выделением фундаментальных элементов познавательной активности. Принцип полноты структуры учебного цикла задаёт исходную системность, которая в процессе собственного развития устанавливает новую целостно-системную сущность. Обобщённая характеристика познавательного процесса выделяет его генетическую определённость[10].

Это определяет основные элементы технологии целостно-системного ускоренного обучения. К ним можно отнести: 1) целостносистемный учебный цикл - как мера ускоренного обучения; 2) системный анализ элементов целостно-системного цикла учебной деятельности; 3) организация многоэтапного процесса формирования учебной деятельности через её интериоризацию. Выполнение технологии формирования знания порождает общий механизм ускоренного обучения целостно-системной структуры.

Запуск ускоренного обучения начинается с объяснения теоретических основ скоростных интеллектуальных способностей, которые порождаются в результате освоения метода системного анализа на примере исследования познавательного цикла и механизма формирования внутреннего знания. При этом рассматривается сверхтонкая структура каждого законченного этапа познавательной активности с выделением ориентировочного, исполнительного и контрольного компонентов деятельности.

В качестве основных целостно-системных признаков ускоренного обучения можно выделить: 1) формирование скоростного целостно-системного навыка, позволяющего дать самую полную характеристику любого процесса; 2) умение организовать учебноисследовательскую деятельность с предварительным анализом планируемых результатов; 3) возможность переноса целостносистемного цикла жизнедеятельности для решения практических задач различной естественной и социальной природы. Это задаёт возможность совершенствования и развития ускоренного обучения.

Основными направлениями развития технологии целостно-системного ускоренного обучения можно считать: 1) разработка общей учебной программы по организации ускоренного обучения нового типа; 2) составление учебных задач по формированию скоростных учебных навыков; 3) формирование методических приёмов по проведению многоэтапной отработки учебного действия; 4) совершенствование критериев сформированности целостносистемного скоростного учебного знания. Эти психолого-педагогические проблемы требуют организации дополнительных исследований.

На первом этапе развития теории и методики целостно-системного ускоренного обучения важно составить обучающую учебную программу по организации нового вида учебной деятельности. Во введении необходимо установить метод изучения ускоренного обучения на основе системного анализа целостно-системного цикла жизнедеятельности. Далее раскрываются инвариантные и многовариантные формы целостно-системных учебных циклов.

Формирование скоростных учебных навыков происходит в результате специальных учебных задач. Тип задачи определяется как соответствующим элементом целостно- 
системного цикла, так и видом действия системного анализа, направленного на его воспроизводство. Проблема поэтапного формирования скоростной познавательной деятельности задаёт дополнительную типологию учебных задач, которая определяется формой существования действия. Поэтому каждая учебная задача имеет тройственную характеристику: элементно-видо-формовую. Например, дать характеристику целостных свойств начального состояния субъекта в знаковой форме.

Проблема формирования скоростного целостно-системного действия определяет разработку методических приёмов по формированию познавательной активности. На первом этапе раскрывается понятие о целостносистемном цикле как условии существования скоростного познавательного действия. Далее выделяется структура целостно-системногоцикла. Формируются представления о системном анализе и его действиях. Устанавливаются технологии воспитания различных форм познавательной деятельности.

Процесс формирования скоростной целостно-системной учебной деятельности требует управления. В качестве нормативной скоростной учебной деятельности можно принять такую познавательную активность, которая отражает воспроизводство всего целостносистемного цикла, направленного на реализацию его структуры относительно системности каждого структурного элемента, проходящего все этапы интерио-экстериоризации, как моменты мгновенного знания. Поэтому главными критериями сформированности можно определить структурность, целостность, системность, этапность и переносность инвариантной формы скоростной целостносистемной учебной деятельности.

Целостно-системный цикл учебной деятельности порождает его скоростное качество, то есть формируются автоматизированные образовательные действия, которые принимают форму соответствующего навыка. При скоростном целостно-системном цикле учебной деятельности объём ориентированной, исполнительной и контрольной учебной информации возрастает в несколько раз. Овладение методом применения целостносистемного цикла в учебной деятельности повышает её оперативность и изменяет форму воспитанного мышления от эмпирического до нормативного творческого.

Запуск скоростного целостно-системного цикла учебной деятельности может начаться практически с любого элемента цикла, когда целевая зависимость приобретает конкретную предметную потребность. То есть происходит фазовый сдвиг целостно-системного цикла на локальное достижение выделенного шага без детальной проработки всех структурных элементов. При этом возникает прямой скоростной целостно-системный цикл учебной деятельности. Он предполагает движение субъекта деятельности к новому собственному «Я» через полную последовательность предметно-деятельностых условий развития цикла.

Скоростной целостно-системный цикл учебной деятельности может иметь многоцелевой характер. Мультипликативность определяется возможностью одновременного решения не только типовых заданий, но и единым конструированием различных подходов в реализации проблемных ситуаций, анализ которых одновременно невозможен при старых стереотипах мышления. Наблюдение за развитием нескольких циклов сразу задаётся единым тиром структуры каждого цикла и стандартный, системный подход к организации единого процесса управления за выделенными проблемами.

1. Запуск скоростного целостно-системного цикла учебной деятельности.

2. Обратный скоростной целостносистемного цикла учебной деятельности.

3. Смешанный скоростной целостносистемного цикла учебной деятельности.

4. Дискретный скоростной целостносистемного цикла учебной деятельности.

5. Интерференция скоростных целостносистемного цикла учебной деятельности.

6. Колебательные скоростные целостносистемного цикла учебной деятельности.

7. Завершённость скоростного целостносистемного цикла учебной деятельности.

Дальнейшее формирование целостносистемного цикла скоростной учебной деятельности даёт возможность изменять направления развёртывания цикла. Можно выделить различные виды целостно-системных циклов ускоренной учебной деятельности. Вид цикла задаётся задачами и целями познавательной активности. То есть существуют обратные, смешанные, дискретные циклы, которые при взаимном существовании могут создавать зоны интерференции, обладать колебательными характеристиками из-за неустановившейся цели деятельности. Как и любое действие скоростной целостно-системный цикл учебной деятельности определяется характеристикой степени завершённости.

Рассмотрим виды целостно-системных скоростных навыков.

1. Скоростной целостно-системный навык.

Многократное повторение типовых целостно-системных учебных действий приводит 
к формированию скоростных учебных навыков соответствующих заданным действиям. Сворачивание цикла может проходить по двум направлениям. Первое - сворачивание и автоматизация видов деятельностей, соединяющих предметные условия цикла. Второе - сокращение времени на взаимодействие с внешними элементами цикла за счёт увеличения масштаба контакта. Рассмотрим каждое из них.

2. Прямой скоростной целостно-системный навык.
3. Обратный
скоростной
целостносистемный навык.

4. Смешанный скоростной целостносистемный навык.

5. Дискретный скоростной целостносистемный навык.

Сворачивание и автоматизация видов деятельности является естественным условием развития деятельности. Постепенное прохождение всех элементов целостносистемного цикла порождает прямое познавательное действие, которое при многократном повторении трансформируется в скоростной целостно-системный навык. Общее сокращение времени прохождения цикла происходит за счёт сокращения фундаментальных компонентов общего действия: ориентировочного, исполнительного и контрольного.

Сформированный прямой скоростной целостно-системный навык может иметь обратную форму. Обратный скоростной навык имеет характер частичной контрольной функции. Когда проверяется выполненное действие в сравнении с достигнутыми результатами. При этом обратное действие приобретает характеристику частичной интериоризации цели развития субъекта с расширением его социальных характеристик.

Формирование гиперпространства целостносистемного цикла ускоренного обучения.

1. Общее представление

гиперпространстве целостно-системного цикла ускоренного обучения.

Множество скоростных целостно-системных циклических навыков образуют гиперпространство целостно-системного ускоренного обучения. Общей целью существования и развития данного вида пространства является совершенствование и формирование личности. Законы социального и экономического роста задают общий диапазон совершенствования субъекта жизнедеятельности, высшей формой которого, по нашему мнению, является целостно-системная личность, организующая собственную активность на основе отражения образа Мира как множество целостносистемных циклов различной природы. Единство их развития и совершенствования определяют гиперпространство целостно-системных циклов всеобщего Мира.

2. Структура гиперпространства целостносистемного цикла ускоренного обучения.

В первом приближении гиперпространство скоростных целостно-системных циклических навыков можно представить в виде расширяющегося конуса, образующие которого есть уравнения линий скорости обучения относительно времени усвоения социального опыта. Высота шага развивающегося цикла определяется дискретными микроцелями совершенствования личности. Плотность шага цикла зависит от утончённости системного анализа развития субъекта жизнедеятельности.

При исследовании сверхтонкой структуры целостно-системного цикла можно выделить три составляющие гиперлинии. Она должна состоять из ориентировочной, исполнительной и контрольных составляющих. В рамках динамической свободы сверхтонких структур можно представить не только их относительное скольжение, но и собственное вращение, направленное на взаимодействие и взаимоуправляемость структур.

Каждый субъект жизнедеятельности формирует собственное гиперпространство скоростного целостно-системного цикла восприятия Мира. Взаимодействие гиперпространств субъектов различной фазы формирования порождают новые законы социальных отношений, направленных на всеобщую Гармонию развития Мира мгновенного восприятия.

Так же можно определить взаимодействие структур гиперпространства целостносистемного цикла ускоренного обучения и формирование гиперпространства целостносистемного цикла ускоренного обучения.

Выделенные три направления эрцгаммности - базисного принципа формирования целостносистемного широкопрофильного специалиста, который отражает три синергетические характеристики всего пространства жизнедеятельности при моделировании его структуры в виде трёх звёзд Эрцгамма при педагогометрическом моделировании: системного учебного предмета, целостносистемного цикла как меры коммуникации и целостно-системных основ ускоренного обучения - формируют обобщённый образ для дальнейшего физико-математического моделирования эрцгамных педагогометрических процессов и создании пакетов прикладных педагогометрических программ анализирующих формирование гиперпространства целостносистемных циклов жизнедеятельности широкопрофильной направленности. 


\section{References:}

1. Mishchik SA (2014) Pedagogometrika and mathematical modeling educational activity. Materialy Mezhdunarodnoy nauchnoy konferenctsii "Modern mathematics in science" - 30.06.2014. ISJ Theoretical \&Applied Science 6(14): 54-56. Caracas, Venezuela. doi: http://dx.doi.org/10.15863/TAS.2014.06.14.10

2. Mishchik SA (2014) Simulation training activity methods of mathematical logic. Materialy Mezhdunarodnoy nauchnoy konferenctsii "Eurapean Science and Education" - 30.07.2014. ISJ Theoretical \&Applied Science 6(15): 72-74 Marseille, France. doi: http://dx.doi.org/10.15863/TAS.2014.07.15.13

3. Mishchik SA (2014) Mathematical modeling system integrity-cycle of life activity - first goal pedagogometriki. Materialy Mezhdunarodnoy nauchnoy konferenctsii "European Applied Sciences" - 30.08.2014. ISJ Theoretical \&Applied Science 7(16): 77-79. Aix-en-Provence, France. doi: http://dx.doi.org/10.15863/TAS.2014.08.16.13

4. Mishchik SA (2014) Mathematical modeling system integrity-curricular activities - the second problem pedagogometriki. Materialy Mezhdunarodnoy nauchnoy konferenctsii "European Innovation" - 30.09.2014. ISJ Theoretical \&Applied Science 9(17): 126-128 Martigues, France. doi: http://dx.doi.org/10.15863/TAS.2014.09.17.21

5. Mishchik SA (2014) Mathematical modeling holistic-systemic communicative activity - the third task pedagogometriki. Materialy Mezhdunarodnoy nauchnoy konferenctsii "European Scientific Achievements" 30.10.2014. ISJ Theoretical \&Applied Science 10(18): 45-47 Brighton, UK. doi: http://dx.doi.org/10.15863/TAS.2014.10.18.11

6. Mishchik SA (2014) Mathematical modeling integrity - system performance subject - fourth task pedagogometriki. Materialy Mezhdunarodnoy nauchnoy konferenctsii "European Science and Technology" 30.11.2014. ISJ Theoretical \&Applied Science 11(19): 51-54 Southampton, UK. doi: http://dx.doi.org/10.15863/TAS.2014.11.19.10

7. Mishchik SA (2014) Star ertsgammy physical and mathematical model integritysystem ability to live. Materialy Mezhdunarodnoy nauchnoy konferenctsii "Eurapean Research" - 30.12.2014. ISJ Theoretical \& Applied Science 12 (20): 57-60 Birmingham, United Kingdom. doi: http://dx.doi.org/10.15863/TAS.2014.12.20.13

8. Tokmazov GV (2014) Matematicheskoe modelirovanie $\mathrm{V}$ uchebno-professional'noy deyatel'nosti. Materialy Mezhdunarodnoy nauchnoy konferentsii «Modern mathematics in science» - 30.06.2014. ISJ Theoretical \& Applied Science 6(14): 44-46. - Caracas, Venezuela.

doi: http://dx.doi.org/10.15863/TAS.2014.06.14.8

9. Tokmazov GV (2014) Analysis says study skills in the study of mathematics. Materialy Mezhdunarodnoy nauchnoy konferenctsii "Eurapean Science and Education" 30.07.2014. ISJ Theoretical \&Applied Science 6(15): 72-74 Marseille, France. doi: http://dx.doi.org/10.15863/TAS.2014.07.15.14

10. Tokmazov GV (2014) Mathematical modeling research skills in educational activity methods of probability theory. Materialy Mezhdunarodnoy nauchnoy konferenctsii "Eurapean Science and Technology" 30.11.2014. ISJ Theoretical \&Applied Science 11(20): 66-69 Southampton, United Kingdom. doi:

http://dx.doi.org/10.15863/TAS.2014.11.19.13 